\title{
Is the postpharyngeal gland of a solitary digger wasp homologous to ants? Evidence from chemistry and physiology
}

\author{
E. Strohm • M. Kaltenpoth $\cdot$ G. Herzner
}

Received: 13 August 2009/Revised: 4 February 2010/Accepted: 8 February 2010/Published online: 2 March 2010

(C) The Author(s) 2010. This article is published with open access at Springerlink.com

\begin{abstract}
The postpharyngeal gland (PPG) was thought to be restricted to ants where it serves a crucial function in the generation of the colony odour. Recently, head glands that closely resemble the PPG of ants were discovered in females of a solitary digger wasp, the European beewolf. The function of this gland necessarily differs from ants: beewolf females apply the secretion of their PPG onto the bodies of paralysed honeybees that serve as larval provisions in order to delay fungus growth. Since ants and digger wasps are not closely related, the occurrence of this gland in these two taxa might either be due to convergent evolution or it is a homologous organ inherited from a common ancestor. Here we test the hypothesis that the PPGs of both taxa are homologous by comparing characteristics of chemical composition and physiology of the PPG of beewolves and ants. Based on reported characteristics of the PPG content of ants, we tested three predictions that were all met. First, the PPG of beewolves contained mainly long-chain hydrocarbons and very few compounds with functional groups. Second, the composition of hydrocarbons in the beewolf PPG was similar to that of the hemolymph. Taking the structure of the gland
\end{abstract}

E. Strohm $(\bowtie) \cdot$ M. Kaltenpoth · G. Herzner

Department of Zoology, University of Regensburg, 93040

Regensburg, Germany

e-mail: erhard.strohm@biologie.uni-regensburg.de

M. Kaltenpoth

e-mail: mkaltenpoth@ice.mpg.de

G. Herzner

e-mail: gudrun.herzner@biologie.uni-regensburg.de

Present Address:

M. Kaltenpoth

Research Group Insect Symbiosis, Max Planck Institute for Chemical Ecology, Hans-Knoell-Str. 8, 07745 Jena, Germany epithelium and the huge requirements of beewolf females for gland secretion into account this result suggests that the content of the PPG is also sequestered from the hemolymph in beewolves. Third, the chemical composition of the PPG and the cuticle was similar in beewolves since cuticular hydrocarbons derive either from the hemolymph or the PPG. Taking the considerable morphological similarities into account, our results support the hypothesis of a homologous origin of the PPG in beewolves and ants.

Keywords European beewolf - Philanthus triangulum . Postpharyngeal gland $\cdot$ Hydrocarbons

\section{Introduction}

Chemical communication is known to be a prerequisite for the functioning of colonies of social insects, particularly in the Hymenoptera. Hence, social bees, wasps, and ants are endowed with a huge variety of exocrine glands that serve tasks in, e.g., nest defence, recruitment, and alarming of nestmates (e.g., Hölldobler and Wilson, 1990). One type of gland that has received much attention because of its significance for social interactions is the postpharyngeal gland (PPG) in ants. It is a paired glove-like evagination of the pharynx and contains mainly long-chain straight and branched hydrocarbons. These hydrocarbons are, at least partly, sequestered from the hemolymph. Moreover due to a continuous exchange between the hemolymph, the PPG, and the cuticle there is typically a high chemical congruency between the PPG content and cuticular hydrocarbons (Soroker et al., 1998; Soroker and Hefetz, 2000). Most important for the function in ants, the content of the PPG is continuously taken up from and delivered to nestmates due to body contact, allogrooming, self grooming, and 
trophallaxis (Vienne et al., 1995; Lenoir et al., 2001; Meskali et al., 1995; Lucas et al., 2004; Hefetz et al., 2001). This process results in a mixing of the cuticular hydrocarbons of individuals (Hefetz et al., 1992; Soroker et al., 1994, 1995, 1998) and, thus, generates a colony's idiosyncratic "Gestalt" odour (Crozier and Dix, 1979; Soroker et al., 1994; Hefetz et al., 1996; Dahbi et al., 1998; Lenoir et al., 1999; Oldham et al., 1999; see also Martin and Drijfhout, 2009). This specific colony odour is crucial for the maintenance of the integrity of an ant colony (Vander Meer et al., 1989; for a review of other proposed functions see Eelen et al., 2006).

The PPG was long considered to be restricted to ants (Hölldobler and Wilson, 1990, Schoeters and Billen, 1997; Lenoir et al., 1999; Martin and Drijfhout, 2009). This, at least implicitly, suggested that the PPG evolved in response to the requirements of a social group to establish a colony odour. Recently, however, a PPG has been described from a solitary digger wasp, the European beewolf Philanthus triangulum (Hymenoptera, Crabronidae, Strohm et al., 2007). Since European beewolves are solitary mass provisioning digger wasps, the function of their PPG necessarily differs from that in ants. Beewolf females apply large amounts of PPG secretion onto the bodies of paralysed honeybees that serve as larval provisions by intensively licking the cuticle of their prey (Strohm and Linsenmair, 2001; Herzner et al., 2007a). This embalming has two effects: it delays fungus growth on the prey (Herzner and Strohm, 2007) and it prevents its desiccation (Herzner and Strohm, 2008) and thus protects the larval provisions against degradation.

Male beewolves also have a PPG (Kroiss et al., 2006; Herzner et al., 2007b). However, due to strong sexual selection its morphology (enlarged unbranched paired tubes) and function (reservoir for the sex pheromone) differ somewhat from females. Therefore, we focus on the PPG of female beewolves.

Although crabronid wasps belong to the aculeate Hymenoptera, they are not closely related to ants (Brothers, 1999). Whereas the Formicidae, together with the Vespidae and Eumenidae, are a part of the super family Vespoidea the crabronid wasps belong to the super family Apoidea and are thought to represent the sister group to the bees (Apidae sensu lato). The wide phylogenetic separation of the taxa suggests a convergent evolution of this gland. However, conspicuous similarities with regard to the overall appearance and location, as well as details of the morphology, and the involvement in a grooming process support the alternative view of a homology of the PPGs of beewolves and ants (Strohm et al., 2007). In this study, we ask whether chemical and physiological aspects of the putative PPG of beewolf females also support the hypothesis of a homology between the PPG of ants and beewolves.
The overall chemical composition of the PPG of beewolf females has already been established (Strohm et al., 2008). The gland contains mainly long-chain hydrocarbons without functional groups. The same can be said of the PPG of ants (e.g., Vander Meer et al., 1982; Hefetz et al., 1992; Soroker et al., 1995). Thus, one prediction following from the homology hypothesis, namely that the overall chemical composition is similar between European beewolves and ants seems to be tentatively supported. However, some details deviate and have to be considered in detail.

In ants, the content of the PPG can be taken up by different mechanisms: it can be sequestered either from the hemolymph, from the cuticle during self grooming, from nestmates' cuticles during allogrooming, or from nestmates during trophallaxis (Meskali et al., 1995; Lucas et al., 2004; Hefetz et al., 2001). The relative importance and distribution of these different mechanisms among ant taxa are not yet established. However, this process results in a high similarity of the composition of the PPG content with the hemolymph (e.g., Soroker et al., 1994, 1995; Kaib et al., 2000; Lucas et al., 2004). As in ants, the PPG of beewolves is basically a reservoir without an associated glandular tissue. It is surrounded by a monolayered epithelium that is apparently too small to produce the large amount of secretion that is necessary for prey embalming. As a consequence, the majority of chemicals in the beewolf PPG are most probably sequestered from the hemolymph. Thus, a second prediction following from the homology hypothesis is that the hydrocarbon profile of the PPG of beewolves is similar to that of the hemolymph.

Due to the extensive self and allogrooming in ants that is accompanied by the delivery and distribution of the PPG secretion (e.g., Bagnères and Morgan, 1991; Soroker et al., 1994; Meskali et al., 1995), and due to the probable transport of hydrocarbons from the hemolymph to both, the PPG and the cuticle (e.g., Soroker and Hefetz, 2000; other insects: Schal et al., 1998; Fan et al., 2003) there is also a similarity of the chemical profile of the PPG with the cuticle. Assuming a similar association between the PPG and the cuticle in beewolves, the third prediction is that the PPG content of beewolves should be similar to the cuticle as well.

To evaluate these predictions, we analysed the chemical composition of the PPG, the hemolymph, and the cuticle of female European beewolves using combined gas chromatography-mass spectrometry (GC-MS) analyses.

\section{Materials and methods}

Previous investigations showed that due to the huge amount of hydrocarbons in the PPG, extracts of entire 
heads are identical to extracts of the dissected glands (Strohm et al., 2008). The heads of 37 freshly killed females were cut off and soaked individually in $0.25 \mathrm{ml}$ distilled $n$-Hexane (Fluka) for $4 \mathrm{~h}$. Cuticular hydrocarbons were obtained from the same 37 beewolf females whose heads had been extracted. To ensure that these extracts were not contaminated with the content of the head gland, only the gaster of each female was used. The gasters were cut off and soaked in $500 \mu \mathrm{l}$ distilled hexane for $10 \mathrm{~min}$.

Preliminary analyses showed that the amount of hydrocarbons in the hemolymph is too small to yield reasonable chromatograms with hexane extracts. Therefore, we used SPME fibres to sample the hydrocarbons of the hemolymph (previous tests confirmed that the results of extraction with hexane and with SPME fibres are practically identical). To avoid any influence of the extraction solvents on the hemolymph, we used different specimens for the analysis of hemolymph. We dissected the gasters of six freshly killed females, removed the hemolymph with a pipette and transferred it to an Eppendorf vial. A SPME fibre coated with a $100-\mu \mathrm{m}$ polydimethylsiloxane film (SUPELCO, Bellefonte, PA, USA) was dragged through the hemolymph of each individual several times and the sample was immediately analysed by GC-MS.

Capillary GC-MS analysis was performed on an Agilent 6890N Series gas chromatograph (Agilent Technologies, Böblingen, Germany) coupled to an Agilent 5973 inert mass selective detector. The GC was equipped with a RH$5 \mathrm{~ms}+$ fused silica capillary column $(30 \mathrm{~m} \times 0.25 \mathrm{~mm}$ ID; $d f=0.25 \mu \mathrm{m}$; temperature program: from 60 to $300^{\circ} \mathrm{C}$ at $5^{\circ} \mathrm{C} / \mathrm{min}$ and held for $1 \mathrm{~min}$ at $60^{\circ} \mathrm{C}$ and for $10 \mathrm{~min}$ at $300^{\circ} \mathrm{C}$ ). Helium was used as the carrier gas with a constant flow of $1 \mathrm{ml} / \mathrm{min}$. A split/splitless injector was installed at $250^{\circ} \mathrm{C}$ in the splitless mode for $60 \mathrm{~s}$. The electron impact mass spectra (EI-MS) were recorded with an ionization voltage of $70 \mathrm{eV}$, a source temperature of $230^{\circ} \mathrm{C}$, and an interface temperature of $315^{\circ} \mathrm{C}$. The software MSD ChemStation for Windows (Agilent Technologies, Palo Alto, CA, USA) was used for data acquisition.

The compounds were identified by comparing retention times and mass spectra of the peaks of the samples with the known composition of the PPG secretion (Strohm et al., 2008) and with data from a commercial MS library (NIST, Gathersburg, MD, USA). There were no additional new peaks.

\section{Statistical analysis}

For the comparison of PPG and cuticle we could use the respective samples of the same females. The PPG samples of these females were compared with the composition of hemolymph samples of another set of females. We analysed the samples with regard to both qualitative congruency as well as quantitative similarity of the relative amounts of the components. For quantitative analyses, peak areas were obtained by automatic integration and the total peak area of each individual extract was standardized to $100 \%$. Because the relative amounts of the components constitute compositional data, they were transformed to log contrasts prior to analysis (Aitchison, 1986; Reyment, 1989). The means of the transformed values for each peak of the different specimens were calculated.

To test for a relationship between the hydrocarbon profile of the head gland, the hemolymph, and the cuticle we conducted regression analyses between the mean proportions of components in the head, the gaster cuticle, and the hemolymph samples. We used reduced major axis (RMA) regressions instead of the usual least squares regression since the variables have the same measurement error and no dependent and independent variable can be specified (Legendre and Legendre, 1998). High similarity would not only require a significant correlation between the components of different samples. Additionally, the regression should show direct proportionality, indicating that the relative amounts of the samples are similar. This means that the slope of the regression line should not differ from 1 and the $y$-intercept should not differ from 0 . Therefore, we calculated the $95 \%$ confidence intervals for slope and $y$-intercept of each regression line. Data had to be $\log$ transformed to achieve normal distributions. The RMA regressions were calculated using the RMA software v.1.17 (Bohonak and van der Linde, 2004; freely available at http://bio.sdsu.edu/pub/andy/RMA.html).

\section{Results}

\section{Content of the PPG}

In full agreement with a previous analysis (Strohm et al., 2008), the PPG samples of this study contained large amounts of hydrocarbons, mainly long-chain alkenes and smaller or trace amounts of alkanes, methylalkanes, and unsaturated ketones (Table 1). As in the earlier study, we found a conspicuous dimorphism with regard to the major peak: it was either (Z)-9-pentacosene or (Z)-9-heptacosene. In the PPG and cuticle samples 29 of the 37 females had (Z)-9-pentacosene and 8 had (Z)-9-heptacosene as the major peak. However, in the hemolymph samples only two of the six females were of the (Z)-9-pentacosene and four were of the (Z)-9-heptacosene-type. Thus, the proportion of individuals that belong to the two chemomorphs differs between PPG and cuticle samples on the one hand and the hemolymph samples on the other hand. However, due to the small sample size of the hemolymph extracts it was not reasonable to analyse the two chemomorphs separately. 
Table 1 Chemical composition of the postpharyngeal gland (PPG, $N=37$ females), the cuticular hydrocarbons of the gaster (same $N=37$ females), and the hemolymph ( $N=6$ other females) of female European beewolves

\begin{tabular}{|c|c|c|c|c|c|c|}
\hline & \multicolumn{2}{|l|}{ PPG } & \multicolumn{2}{|c|}{ Cuticle } & \multicolumn{2}{|c|}{ Hemolymph } \\
\hline & Mean & SD & Mean & SD & Mean & SD \\
\hline Heneicosane & 0.20 & 0.14 & 0.14 & 0.07 & 0.63 & 0.38 \\
\hline Docosane & 0.15 & 0.09 & 0.18 & 0.10 & 0.47 & 0.21 \\
\hline Tricosenes & 0.30 & 0.26 & 0.19 & 0.19 & 1.31 & 1.04 \\
\hline Tricosane & 13.80 & 3.59 & 16.80 & 8.13 & 17.30 & 0.92 \\
\hline Methyltricosanes & 0.09 & 0.09 & 0.12 & 0.10 & 0.58 & 0.95 \\
\hline Tetracosene & 0.97 & 0.73 & 0.88 & 0.45 & 1.12 & 1.06 \\
\hline Tetracosane & 0.16 & 0.10 & 0.46 & 0.28 & 0.36 & 0.20 \\
\hline Pentacosenes & 62.50 & 29.80 & 53.40 & 27.00 & 27.40 & 28.00 \\
\hline Pentacosane & 2.22 & 1.02 & 7.33 & 3.97 & 5.94 & 0.94 \\
\hline Methylpentacosanes & 0.06 & 0.03 & 0.08 & 0.05 & 0.18 & 0.20 \\
\hline Hexacosene & 0.45 & 0.70 & 0.50 & 0.59 & 1.89 & 1.09 \\
\hline Hexacosane & 0.05 & 0.03 & 0.22 & 0.24 & 0.01 & 0.04 \\
\hline 16-Pentacosen-8-one & 0.94 & 0.74 & 0.67 & 0.73 & 0.35 & 0.36 \\
\hline Heptacosene & 15.90 & 29.00 & 14.20 & 25.30 & 36.10 & 24.70 \\
\hline Heptacosane & 0.37 & 0.20 & 1.67 & 1.14 & 1.82 & 0.94 \\
\hline Octacosane & 0.03 & 0.02 & 0.15 & 0.19 & 0.04 & 0.09 \\
\hline 18-Heptacosen-10-one & 1.17 & 4.59 & 0.60 & 0.88 & 1.60 & 1.53 \\
\hline Nonacosene & 0.24 & 0.43 & 0.29 & 0.55 & 1.33 & 1.05 \\
\hline Nonacosane & 0.30 & 0.27 & 1.62 & 1.11 & 1.22 & 0.38 \\
\hline Hentriacontene & 0.02 & 0.04 & 0.04 & 0.06 & 0.03 & 0.08 \\
\hline Hentriacontane & 0.07 & 0.07 & 0.49 & 0.43 & 0.26 & 0.17 \\
\hline
\end{tabular}

Given are mean and standard deviation (SD) of the percent peak areas of the different components

Lumping these data is conservative with regard to the hypothesis tested since different proportions of chemomorphs in the groups rather reduce similarity than enhance it.

Since the amount of hydrocarbons was low in some of the individual samples (in particular in the hemolymph) we were not able to detect all substances that were described as components of the PPG obtained by pooling individuals (Strohm et al., 2008). In particular the trace amounts of a sesquiterpene, a methylester and a long-chain unsaturated alcohol could not be detected in this study. Furthermore, some peaks could not be satisfactorily separated to allow reliable quantification and had to be combined for the analysis. The following compounds were combined: $\Delta-X$ tricosene, (Z)-9-tricosene (by far the most abundant) and $\Delta$-7-tricosene were combined as tricosenes; 11 -methyl tricosane, 9-methyl tricosane, 7-methyl tricosane, 5-methyl tricosane were combined as methytricosanes; (Z)-9-pentacosene (by far the most abundant) and $\Delta-X$-pentacosene were combined as pentacosenes; 11-methyl pentacosane, 9-methyl pentacosane, and 7-methyl pentacosane were combined as methylpentacosenes. Overall, we could

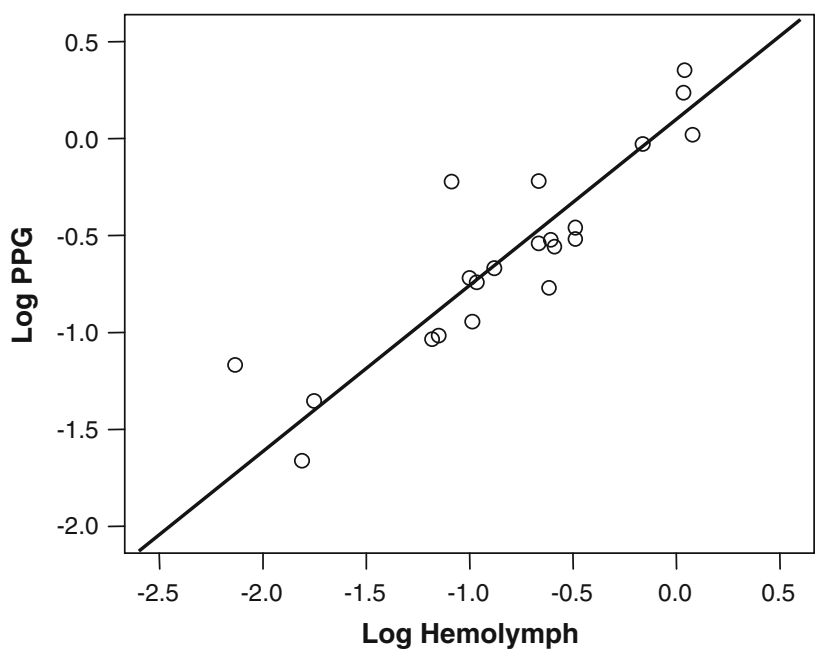

Fig. 1 Results of a reduced major axis linear regression between the relative amount of a particular component in the hemolymph of a group of six beewolf females and in the postpharyngeal gland (PPG) of another group of 37 beewolf females (data Log transformed to comply with normality assumptions)

unambiguously quantify 21 peaks and used these for statistical analysis.

\section{Comparison between PPG and hemolymph}

The comparison of the mean proportions of compounds in the PPG samples $(N=37)$ and the hemolymph samples $(N=6)$ revealed a high overall similarity (Table 1$)$. All hydrocarbon peaks that occurred in the PPG also occurred in the hemolymph. Due to the different proportions of females with (Z)-9-pentacosene and (Z)-9-heptacosene as their major peak, the means differ somewhat in particular for these compounds. Moreover, the accuracy of the assessment of the relative proportions of hydrocarbons in the hemolymph suffers from overall small amounts. Nevertheless, there was a strong linear association between the relative amounts found in the hemolymph and in the PPG (Fig. 1, Table 2). The RMA regression revealed that the $y$-intercept was not different from zero and the slope not different from one, suggesting direct proportionality. This is consistent with the prediction of a high similarity of hydrocarbons in the hemolymph and in the PPG.

\section{Comparison between PPG and cuticle}

The hydrocarbon profile of the cuticle was also very similar to the PPG (Table 1). There were no peaks that occurred exclusively in the PPG or on the cuticle. The chemotype of cuticle and PPG of an individual female was always the same. Moreover, the relative amounts of peaks on the gaster showed a strong linear correlation with the 
Table 2 Results of the RMA regression analysis of the chemical composition of the hemolymph, PPG content, and gaster cuticle of female European beewolves

\begin{tabular}{|c|c|c|c|c|}
\hline & $y$-intercept $(95 \% \mathrm{CI})$ & Slope $(95 \%$ CI $)$ & $R$ & $P$ \\
\hline Hemolymph vs. PPG & $-0.10(-0.29,0.09)$ & $1.16(0.95,1.49)$ & 0.89 & $<0.001$ \\
\hline PPG vs. cuticle & $0.062(-0.11,0.23)$ & $1.06(0.84,1.27)$ & 0.91 & $<0.001$ \\
\hline Hemolymph vs. cuticle & $0.036(-0.20,0.27)$ & $0.81(0.58,1.05)$ & 0.80 & $<0.001$ \\
\hline
\end{tabular}

Given are the $y$-intercept and its 95\% confidence intervals (CI), the slope and its 95\% confidence intervals, the correlation coefficient $R$ and the significance level $P . N=21$ peaks in all cases. In all cases the $95 \%$ CIs of the $y$-intercept include zero and the $95 \%$ confidence intervals of the slopes include one and, thus, suggest direct proportionality

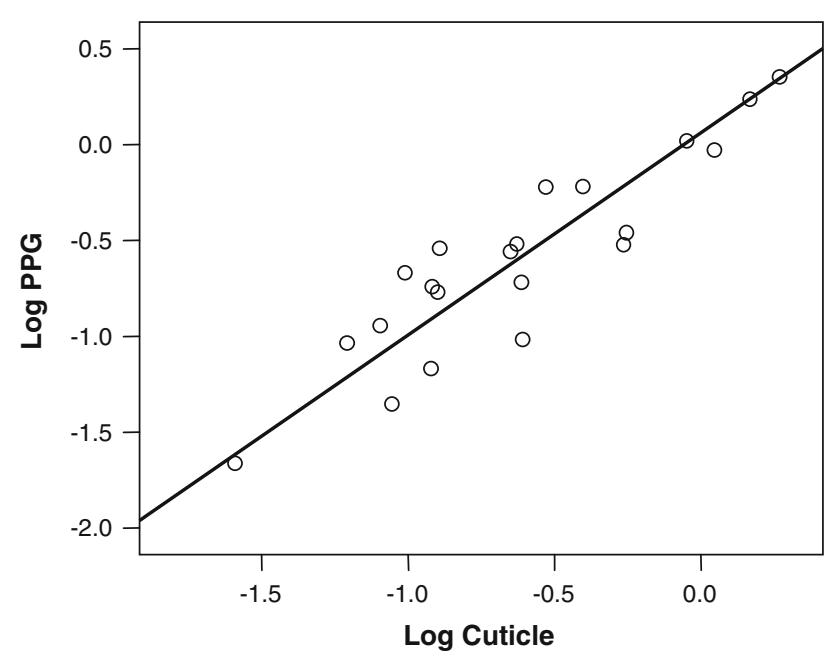

Fig. 2 Results of a reduced major axis linear regression between the relative amount of a particular component in the PPG and on the cuticle (gaster) of the same 37 beewolf females (data Log transformed to comply with normality assumptions)

corresponding peaks in the PPG (Fig. 2, Table 2). Again, the $y$-intercept and the slope of the RMA regression are consistent with a direct proportionality of the components' proportions. Thus, consistent with our prediction, the chemical compositions of the PPG and the cuticle were very similar.

For completeness, we also analysed the similarity between hemolymph and cuticle. We obtained the expected results: the relative amounts of their components were very similar and showed a strong association with direct proportionality (Tables 1,2).

\section{Discussion}

The PPG of beewolf females contains predominantly unbranched unsaturated long-chain hydrocarbons, smaller amounts of saturated hydrocarbons, and minor amounts of unsaturated ketones, methyl-alkanes, trace amounts of saturated ketones, a sesquiterpene, a methylester, and a long-chain unsaturated alcohol (Strohm et al., 2008). The PPG of ants also contain mainly hydrocarbons but mostly saturated and branched hydrocarbons (mono-, di-, and trimethylalkanes) as well as minor proportions of esters, and acids (Vander Meer et al., 1982; Hefetz et al., 1992; Soroker et al., 1995, though ants show some interspecific variation, e.g., Soroker et al., 1998; Soroker and Hefetz, 2000). The most striking difference in the composition of the PPG content of beewolves and ants is the occurrence of small amounts of long-chain unsaturated ketones in beewolves. These ketones have only rarely been described in nature at all. The function of these ketones in the PPG of beewolves is not known. Since the PPG secretion is used by beewolf females to preserve their prey, paralysed honeybees, the ketones might have some antifungal effect. However, bioassays with the female PPG secretion did not reveal such a direct chemical effect (Herzner et al., 2007a). Despite these differences with regard to some minor components, the chemical composition of the PPG content of beewolf females broadly resembles that of the PPGs of ants in that both contain primarily long-chain hydrocarbons without functional groups.

The prevalence of long-chain unsaturated hydrocarbons in the PPG of beewolf females as opposed to the branched alkanes in ants is probably due to their assumed main function, the preservation of the paralysed honeybees in the brood cells. This preservation seems to be mainly accomplished by a physical mechanism (Herzner and Strohm, 2007). The secretion prevents the condensation of water on the bees and, thus, impairs the growth conditions for fungi. The molecular mechanism is as yet unclear. Presumably, the PPG secretion covers structures on the paralysed bee that would otherwise function as effective nuclei for the condensation of water. Scanning electron microscopy revealed that the PPG secretion forms a contiguous layer over the whole surface of the prey. Unsaturated long-chain hydrocarbons might be ideal compounds to build up such a contiguous coating (Herzner and Strohm, 2007, 2008). Thus, the predominance of alkenes in beewolves instead of alkanes and methylalkanes found in ant PPGs may be the result of natural selection for a secretion with particular physicochemical properties that is effective in preserving the prey from fungus growth. We conclude that the small differences in PPG chemistry between beewolves and ants 
are due to differences in the function of the secretion. This does not contradict a similar basic physiology of the gland in both taxa and is consistent with our first prediction of an overall similarity of chemical compounds of the PPG of beewolves and ants.

The hydrocarbon profiles of both the cuticle and the hemolymph of beewolf females appear to be nearly identical to the profile of the PPG. These results suggest that the content of the PPG is sequestered from the hemolymph. It can be estimated that a beewolf female has to produce a mean amount of about $300 \mu \mathrm{g}$ of PPG secretion per day (the average number of bees hunted per day is three (Strohm and Linsenmair, 1997) and the average amount of PPG secretion on a bee is about $100 \mu \mathrm{g}$ (Herzner et al., 2007a). The PPG is basically a glove-like structure without any distinct glandular cells associated with this reservoir. Moreover, the walls of the PPG are formed by a thin monolayered epithelium (Strohm et al., 2007) that does not show any obvious signs of a high metabolic activity like multiple nucleoli. Therefore, it is unlikely that the epithelium has the capacity to synthesize the large amounts of hydrocarbons required for prey preservation. Most probably, the compounds are synthesised in oenocytes in the fat body and are transported to the PPG via the hemolymph as has been suggested for ants (Soroker et al., 1995; Soroker and Hefetz, 2000; Lenoir et al., 1999; Lucas et al., 2004; Eelen et al., 2006). This strongly supports our second prediction, that the content of the PPG is sequestered from the hemolymph. Likewise, our results suggest that the same hydrocarbons are transported to the cuticular epithelium by the hemolymph and are secreted onto the cuticle as has been shown in several insects besides ants (Schal et al., 1998; Fan et al., 2003) or that cuticular hydrocarbons from the PPG are spread over the surface during grooming. Thus, the third prediction of a similarity between the PPG profile and the cuticle is also supported.

Our results on the chemical composition of the PPG content, its congruency with both the hemolymph and the cuticle, and the probable sequestration of the chemicals into the PPG from the hemolymph are consistent with the hypothesis that the PPGs of beewolves and ants are homologous. This conclusion is supported by the similarities in location, morphology, and ultrastructure as well as the involvement of the PPG in a grooming-like behaviour both in beewolves and ants (Strohm et al., 2007; Strohm and Linsenmair, 2001). Thus, the view of the PPG in ants as an organ that might have evolved de novo in response to the requirements of the social lifestyle has probably to be revised. Our results strongly suggest that the PPG was already present in a common ancestor of ants and beewolves.

Still, the alternative explanation that the occurrence of such similar organs in distant taxa is the result of convergent evolution cannot be finally rejected. Assuming that no other taxa of the Hymenoptera possess a PPG, a homologous origin would mean that the organ was lost in all taxa except beewolves and ants (Strohm et al., 2007). A priori, this seems rather unlikely. Thus, a final conclusion about a homologous origin might have to be postponed until other taxa have been checked for a PPG.

Acknowledgments This study was partly supported by the German Science Foundation (DFG: STR 532/1-2). MK was supported by the Volkswagen foundation (VW I/82682) through a postdoctoral fellowships.

Open Access This article is distributed under the terms of the Creative Commons Attribution Noncommercial License which permits any noncommercial use, distribution, and reproduction in any medium, provided the original author(s) and source are credited.

\section{References}

Aitchison J. 1986. The Statistical Analysis of Compositional Data. Chapman \& Hall, London, 416 pp

Bagnères A.G. and Morgan E.D. 1991. The postpharyngeal glands and the cuticle of Formicidae contain the same characteristic hydrocarbons. Experientia 47: 106-111

Bohonak A.J. and van der Linde K. 2004. RMA: Software for Reduced Major Axis regression for Java. http://www.kimvdlinde. com/professional/rma.html

Brothers D.J. 1999. Phylogeny of wasps, ants and bees (Hymenoptera, Chrysidoidea, Vespoidea and Apoidea). Zool. Scr. 28: 233-249

Crozier R.H. and Dix M.W. 1979. Analysis of 2 genetic models for the innate components of colony odor in social Hymenoptera. Behav. Ecol. Sociobiol. 4: 217-224

Dahbi A., Cerda X. and Lenoir A. 1998. Ontogeny of colonial hydrocarbon label in callow workers of the ant Cataglyphis iberica. C.R. Acad. Sci. Ser. 3 321: 395-402

Eelen D., Børgesen L. and Billen J. 2006. Functional morphology of the postpharyngeal gland of queens and workers of the ant Monomorium pharaonis (L.). Acta Zool. 87: 101-111

Fan Y.L., Zurek L., Dykstra M.J. and Schal C. 2003. Hydrocarbon synthesis by enzymatically dissociated oenocytes of the abdominal integument of the German cockroach, Blatella germanica. Naturwissenschaften 90: 121-126

Hefetz A., Errard C. and Cojocaru M. 1992. Heterospecific substances in the postpharyngeal gland secretion of ants reared in mixed groups. Naturwissenschaften 79: 417-420

Hefetz A., Errard C., Chambris A. and Le Negrate A. 1996. Postpharyngeal gland secretions as a modifier of aggressive behavior in the myrmicine ant Manica rubida. J. Insect Behav. 9: 709-717

Hefetz A., Soroker V., Dahbi A., Malherbe M.C. and Fresneau D. 2001. The front basitarsal brush in Pachycondyla apicalis and its role in hydrocarbon circulation. Chemoecology 11: 17-24

Herzner G., Schmitt T., Peschke K., Hilpert A. and Strohm E. 2007a. Food wrapping with the postpharyngeal gland secretion by females of the European beewolf Philanthus triangulum. J. Chem. Ecol. 33: 849-859

Herzner G., Goettler W., Kroiss J., Purea A., Webb A.G., Jakob P.M., Rössler W. and Strohm E. 2007b. Males of a solitary wasp possess a postpharyngeal gland. Arthropod Struct. Dev. 36: 123133 
Herzner G. and Strohm E. 2007. Fighting fungi with physics: food wrapping by a solitary wasp prevents water condensation. Curr. Biol. 17: R46-R47

Herzner G. and Strohm E. 2008. Food wrapping by females of the European Beewolf, Philanthus triangulum, retards water loss of larval provisions. Physiol. Entomol. 33: 101-109

Hölldobler B. and Wilson E.O. 1990. The Ants. Springer, Heidelberg, $732 \mathrm{pp}$

Kaib M., Eisermann B., Schoeters E., Billen J., Franke S. and Francke W. 2000. Task-related variation of postpharyngeal and cuticular hydrocarbon compositions in the ant Myrmicaria eumenoides. J. Comp. Physiol. A. 186: 939-948

Kroiss J., Schmitt T., Schreier P., Strohm E. and Herzner G. 2006. A selfish function of a "social" gland? A postpharyngeal gland functions as a sex pheromone reservoir in males of the solitary wasp Philanthus triangulum. J. Chem. Ecol. 32: 2763-2776

Legendre P. and Legendre L. 1998. Numerical Ecology, 2nd edn. Elsevier, Amsterdam, $870 \mathrm{pp}$

Lenoir A., Hefetz A., Simon T. and Soroker V. 2001. Comparative dynamics of gestalt odour formation in two ant species Camponotus fellah and Aphaenogaster senilis (Hymenoptera: Formicidae). Physiol. Entomol. 26: 275-283

Lenoir A., Fresneau D., Errard C. and Hefetz A. 1999. Individuality and colonial identity in ants: the emergence of the social representation concept. In: Information Processing in Social Insects (Detrain C., Deneubourg J.L. and Pasteels J.M., Eds). Birkhäuser, Basel, pp 219-237

Lucas C., Pho D.B., Fresneau D. and Jallon J.M. 2004. Hydrocarbon circulation and colonial signature in Pachycondyla villosa. $J$. Insect Physiol. 50: 595-607

Martin S.J. and Drijfhout F.P. 2009. Nestmate and task cues are influenced and encoded differently within ant cuticular hydrocarbon profiles. J. Chem. Ecol. 35: 368-374

Meskali M., Bonavita-Cougourdan A., Provost E., Bagnères A.G., Dusticier G. and Clement J.L. 1995. Mechanism underlying cuticular hydrocarbon homogeneity in the ant Camponotus vagus (Scop) (Hymenoptera, Formicidae)-Role of postpharyngeal glands. J. Chem. Ecol. 21: 1127-1148

Oldham N.J., Morgan E.D., Agosti D. and Wehner R. 1999. Species recognition from postpharyngeal gland contents of ants of the Cataglyphis bicolor group. J. Chem. Ecol. 25: 1383-1393

Reyment R.A. 1989. Compositional data analysis. Terra Nova 1: 2934
Schal C., Sevala V.L., Young H.P. and Bachmann J.A.S. 1998. Sites of synthesis and transport pathways of insect hydrocarbons: cuticle and ovary as target tissues. Am. Zool. 38: 382-393

Schoeters E. and Billen J. 1997. The post-pharyngeal gland in Dinoponera ants (Hymenoptera: Formicidae): unusual morphology and changes during the secretory process. Int. J. Insect Morph. Embryol. 26: 443-447

Soroker V., Fresneau D. and Hefetz A. 1998. Formation of colony odor in ponerine ant Pachycondyla apicalis. J. Chem. Ecol. 24: 1077-1090

Soroker V. and Hefetz A. 2000. Hydrocarbon site of synthesis and circulation in the desert ant Cataglyphis niger. J. Insect Physiol. 46: $1097-1102$

Soroker V., Vienne C. and Hefetz A. 1994. The postpharyngeal gland as a "Gestalt" organ for nestmate recognition in the ant Cataglaphis niger. Naturwissenschaften 81: 510-513

Soroker V., Vienne C. and Hefetz A. 1995. Hydrocarbon dynamics within and between nestmates in Cataglyphis niger (Hymenoptera: Formicidae). J. Chem. Ecol. 21: 365-377

Strohm E., Herzner G. and Goettler W. 2007. A 'social' gland in a solitary wasp? The postpharyngeal gland of female European beewolves (Hymenoptera, Crabronidae). Arthropod Struct. Dev. 36: 113-122

Strohm E., Herzner G., Kaltenpoth M., Boland W., Schreier P., Geiselhardt S., Peschke K. and Schmitt T. 2008. The chemistry of the postpharyngeal gland of female European beewolves. J. Chem. Ecol. 34: 575-583

Strohm E. and Linsenmair K.E. 1997. Female size affects provisioning and sex allocation in a digger wasp. Anim. Behav. 54: 23-34

Strohm E. and Linsenmair, K.E. 2001. Females of the European beewolf preserve their honeybee prey against competing fungi. Ecol. Entomol. 26: 198-203

Vander Meer R.K., Saliwanchik D. and Lavine B. 1989. Temporal changes in colony cuticular hydrocarbon patterns of Solenopsis invicta implications for nestmate recognition. J. Chem. Ecol. 15 : 2115-2126

Vander Meer R.K., Glancey B.M. and Lofgren C.S. 1982. Biochemical changes in the crop, oesophagus and postpharyngeal gland of colony-founding red imported fire ant queens (Solenopsis invicta). Insect Biochem. 12: 123-127

Vienne C., Soroker V. and Hefetz A. 1995. Congruency of hydrocarbon patterns in heterospecific groups of ants: transfer and/or biosynthesis? Insect. Soc. 42: 267-277 